increase in interest in field studies; suitable areas may be overused by visiting parties, some already are. If schools can transfer their interest to those eyesores, the rubbish tips, which are an almost inevitable foature of urban life, then "real" countryside can be spared. Mr Darlington shows how effective tips and refuse heaps are for quantitative ecological investigations of the kind that are an essential part in the training of biologists and responsible citizens.

J. D. CARTHY

\section{CHARMS OF A NATIONAL PARK}

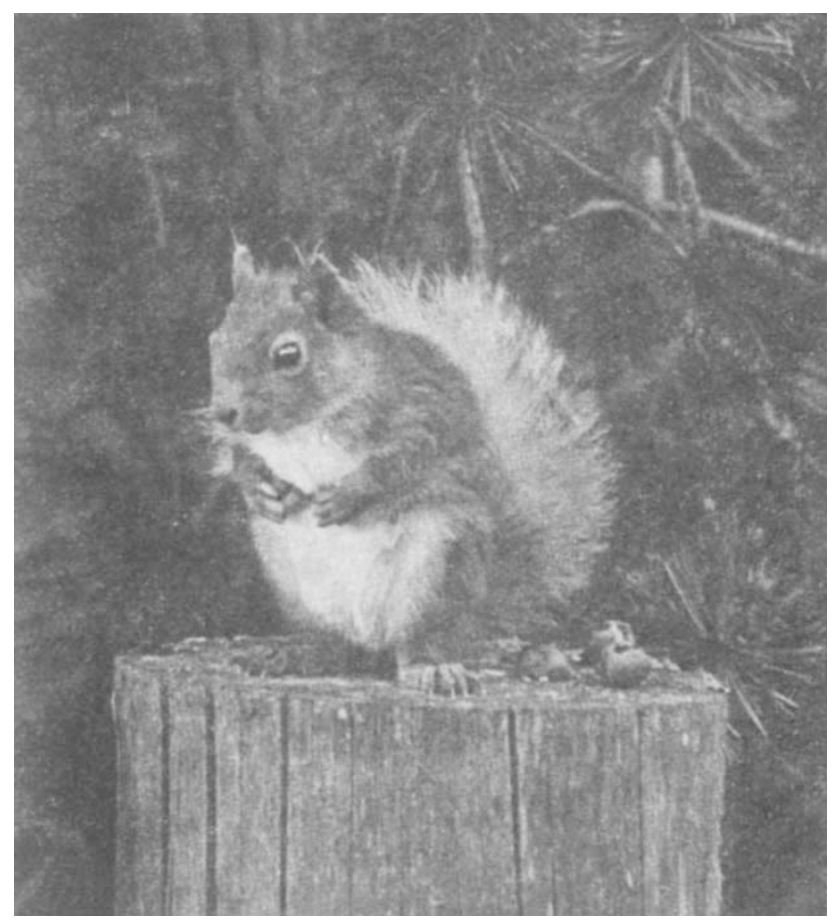

The English Lake District has many charms besides its spectacular and varied scenery, not the least being its interesting wildlife which is to be found in such diverse habitats as sand dune, moorland, woodland, stream, crag and slope and, of course, lake and tarn. Those visitors and naturalists who like to seek out the treasures of this national park will therefore be interested in a new book, from which this photograph of a red squirrel is taken, called Natural History of the Lake District (Warne: London and New York, March 1970, 60s) which has been edited by Canon G. A. K. Hervey and J. A. G. Barnes. Besides contributions on the flora and fauna, there is an opening section on the area's geology and terrain, and at the end, information is provided about the organizations with natural history interests in the park.

\section{INTIMATE BIOLOGY}

Secrets of Plant Life

By Marcel Sire. Translated and with a preface by M. B. E. Godward. Tp. 239. (Collins: London, April 1970.) $126 s$

The Pictorial Encyclopedia of Insects

By V. J. Stanek. I'p. 544. (Hamlyr: London and Now York, February 1970.) $30 \mathrm{~s}$.

Is the growing fashion for ecology providing a market for lavish and expensive biological picture books? Some such phenomenon must surely be invoked to explain the production of so extravagant a book as Marcel Sire's Secrets of Plant Life. This reveals in true and brilliant colours the intimate and unseen details of anatomy and development in many different plants. Many ultra close- up photographs are accompanied by an explanatory text and a sprinkling of prose and verse quotations.

There is no doubt that the photographs are romarkable, substituting for the hand lens, as the translator, Professor Godward, suggests. Fireside botanists with six guineas to spare will be able to learn about petals and sepals, pistils and pollen, ovules and sori, as well as being painlessly introduced to the elassification of plants. But they will not find a treasury of pure beauty in this book; some of the pictures have an unpleasantness that suggests science fiction. Thero is something menacing about the double page picture of the spreading green lobes of the liverwort Marchantia polymorpha, and the sprouting potato at close quarters is far from delightful. There are plenty of attractive pictures, however, and a careful reading will reveal to the amateur a great deal of botanical information. Botanists may prefer just to look at the pictures, but then they probably will not be able to afford the book anyway.

Dr Stanok's The Pictorial Encyclopedia of Insects, has its price to commend it, although even that is hardly an excuse for an irritating lack of organization. The trouble is that this book, with more than a thousand splendid pictures, does not have what seems to be one of the essential characteristics of an encyclopaedia-it is not possible to open it at any page and see at a glance what group is under discussion. If you read the book from the beginning, you will discern that the insects are dealt with in systematic order, but if you are just browsing or using the book for refercnce, you aro likely to open at a page which tells you something like "The third suborder, the white flies Aleuroidina, consists of tiny sap-sucking insects ...". You then have to search back through twelve pages to find out that the order, of which this is the third suborder, is the Homoptera. An inadequate uso of subdivisions and headings, and a confused nomenclature, make this book most frustrating to use.

The book has its value, however, in its comprehensive coverage of insect life and in its useful introduction to insect anatomy and physiology. Its strongest appeal will probably be to the young entomologist interested in the pictures, and not unduly worried by a translation that occasionally provides such evocative descriptions as "The caterpillars, which are green and equipped with horns, foed on the strawberry tree... .".

\section{Mary Lindley}

\section{SCORPION-LIKE ARACHNIDS}

The Biology of Pseudoscorpions

By Peter Weygoldt. (Harvard Books in Biology, No. 6.) Pp. xiv +145 , (Harvard University Press: Cambridge, Massachusetts; Oxford University Pross: London, February 1970.) $58 s$.

THE false-scorpions constitute an order of arachnids that has but seldom been given the concentrated attention of a specialist, and this book will receive and deserve an unqualified welcome from zoologists in general and arachnologists in particular.

Dr Weygoldt, worthy successor to J. C. Chamberlin and M. Beier, has devoted ten years to the study of these fascinating animals, and his book now touches every aspect of their biology. Opening with a description of external and internal structure and physiology, it procoeds to an account of general behaviour, in which the striking character of those arachnids is clearly emphasized. Their ecology, so far as it is known, receives adequate attention, and such topies as phoresy, parasites and distribution are not forgotten.

The longest sections of the book deal with the embryology, the "courtship", here more aptly termed mating dances, the use of the spermatophore, the remarkable development of the young and the care they receive from their mothers. These are topics to which tho author 